\title{
Compact Dual-Band Dipole Antenna with Asymmetric Arms for WLAN Applications
}

\author{
Chung-Hsiu Chiu, ${ }^{1}$ Chun-Cheng Lin, ${ }^{2}$ Chih-Yu Huang, ${ }^{3}$ and Tsai-Ku Lin ${ }^{1}$ \\ ${ }^{1}$ Department of Physics, National Kaohsiung Normal University, Kaohsiung 802, Taiwan \\ ${ }^{2}$ Department of Mathematic and Physical Sciences, R.O.C. Air Force Academy, Kaohsiung 820, Taiwan \\ ${ }^{3}$ Department of Electronic Engineering, National Kaohsiung Normal University, Kaohsiung 802, Taiwan
}

Correspondence should be addressed to Chun-Cheng Lin; cclincafa@gmail.com

Received 6 January 2014; Accepted 12 February 2014; Published 17 March 2014

Academic Editor: Yingsong Li

Copyright (C) 2014 Chung-Hsiu Chiu et al. This is an open access article distributed under the Creative Commons Attribution License, which permits unrestricted use, distribution, and reproduction in any medium, provided the original work is properly cited.

A dual-band dipole antenna that consists of a horn- and a C-shaped metallic arm is presented. Depending on the asymmetric arms, the antenna provides two $-10 \mathrm{~dB}$ impedance bandwidths of $225 \mathrm{MHz}$ (about $9.2 \%$ at $2.45 \mathrm{GHz}$ ) and $1190 \mathrm{MHz}$ (about $21.6 \%$ at $5.5 \mathrm{GHz}$ ), respectively. This feature enables it to cover the required bandwidths for wireless local area network (WLAN) operation at the $2.4 \mathrm{GHz}$ band and 5.2/5.8 GHz bands for IEEE $802.11 \mathrm{a} / \mathrm{b} / \mathrm{g}$ standards. More importantly, the compact size $(7 \mathrm{~mm} \times 24 \mathrm{~mm})$ and good radiating performance of the antenna are profitable to be integrated with wireless communication devices on restricted RF-elements spaces.

\section{Introduction}

Recently, wireless local area network (WLAN) has been one of the most significant applications of the wireless communication technology due to its rapid growth and abundant demands of short-range radio systems. WLAN is restricted by several communication standards, such as IEEE 802.11 a $(2400-2480 \mathrm{MHz})$ and IEEE $802.11 \mathrm{~b} / \mathrm{g}(5150-5825 \mathrm{MHz})$. Hence, high-performance dual-band antennas are widely developed. Among dual-band antennas, the asymmetric dipole antenna is a promising candidate because it provides two distinct resonant modes for achieving dual-band operation. In previous studies, a meandered strip was embedded as an unequal-arms dipole antenna for WLAN operation in 2.4 and $5.2 \mathrm{GHz}$ bands [1]. An asymmetry structure of printed dipole antenna with a double-sided and center-feed design for dual-band $(2.4 / 5 \mathrm{GHz})$ WLAN applications was reported [2]. A printed dipole antenna consisted of two asymmetric tapered arms [3] and an asymmetric dipole composed of a meandered feed line connected to a rectangular radiating element and its asymmetric counterpart with C-shaped parasitic strip [4] were advanced. A rectangular and a circular radiating element acting as asymmetric arms of a dipole to cover $2.4 / 5.2 / 5.8 \mathrm{GHz}$ WLAN bands was employed [5]. A top-loading, an asymmetric coplanar waveguide, and a stepped-feeding structure for WLAN and long term evolution (LTE) operations were demonstrated [6]. However, they still have some drawbacks. For example, the unequal-arms dipole [1] cannot provide $5.8 \mathrm{GHz}(5725-5875 \mathrm{MHz})$ band operation. The double-sided configuration $[2,5]$ may raise manufacturing difficulty and cost. The uniplanar asymmetric dipole [3] still occupied a large area $(44 \mathrm{~mm} \times 15 \mathrm{~mm})$. The constitutions $[4,6]$ were complex, which may curtail the radiating performance (lower gain value and higher crosspolarization level).

In this paper, a dual-band dipole antenna with asymmetric metallic arms for wireless local area network (WLAN) operations is proposed. By varying the angle of two radiating arms, the proposed antenna can achieve $2.4 \mathrm{GHz}(2400-$ $2484 \mathrm{MHz})$ and $5 \mathrm{GHz}(5150-5825 \mathrm{MHz})$ bands for IEEE $802.11 \mathrm{a} / \mathrm{b} / \mathrm{g}$ standards. Simultaneously, the simple geometry provides an easy fabrication and a reasonable cross-polarization level. Its compact size $(7 \mathrm{~mm} \times 24 \mathrm{~mm})$ is satisfactory to be installed in narrow locations of wireless devices. Details 


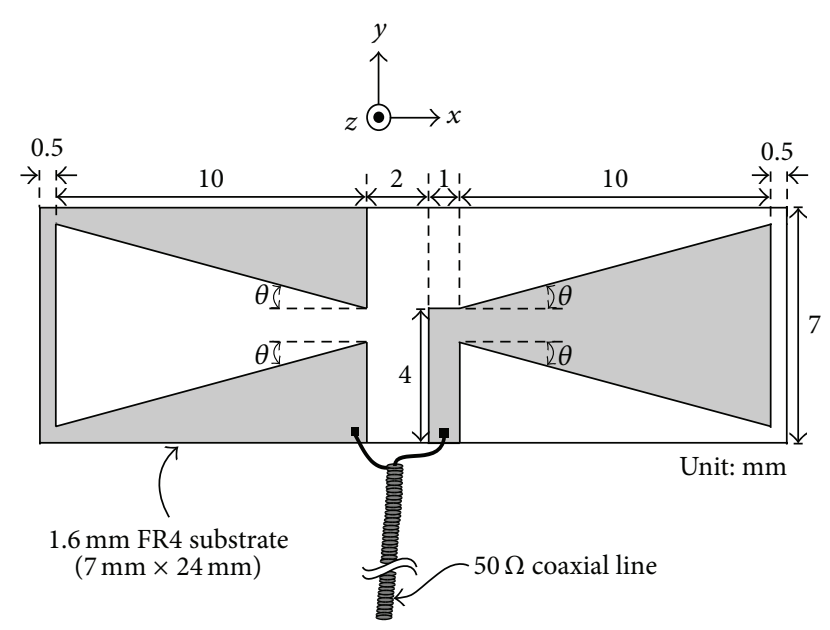

(a)

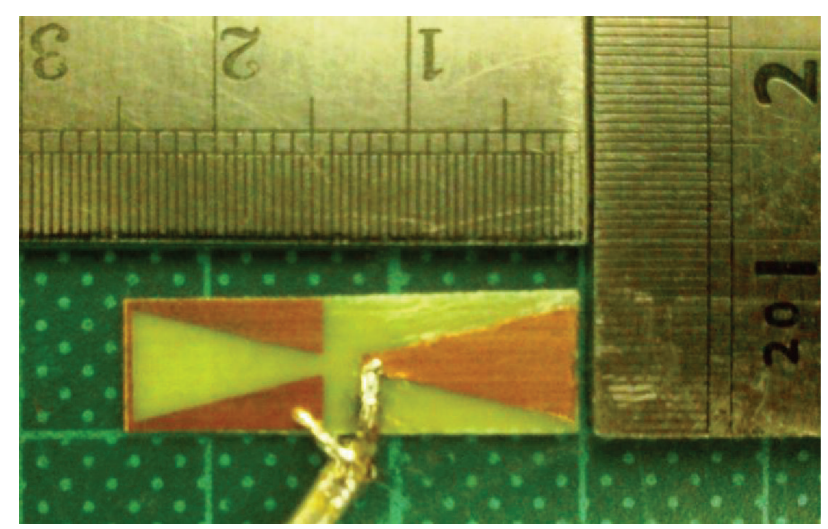

(b)

Figure 1: (a) Geometry and (b) photograph of proposed dual-band dipole antenna for WLAN applications.

of the design concepts are described and the experimental results of the constructed prototype are discussed.

\section{Antenna Design and Experimental Results}

Figure 1 shows the geometry of the proposed dual-band dipole antenna with asymmetric arms for $2.4 / 5.2 / 5.8 \mathrm{GHz}$ WLAN applications. The antenna was printed on an FR4 dielectric substrate with size of $7 \mathrm{~mm} \times 24 \mathrm{~mm}$, thickness of $1.6 \mathrm{~mm}$, and relative permittivity $\varepsilon_{r}=4.4$. A $50 \Omega$ coaxial line was introduced for feeding the RF signal. The dipole antenna was composed of two radiating elements: a horn- and a Cshaped metallic arm.

Figure 2 shows the simulated and measured return loss as a function of $\theta$ of the horn- and C-shaped metallic arm versus frequency. In this experiment, the simulations were computed with Ansoft HFSS and the measurements were obtained with an R\&S ZVB 40 vector network analyzer. Obviously, the lower band shifts toward lower frequency whereas the upper band changes slightly as $\theta$ varied from $0^{\circ}$ to $14^{\circ}$. For the lower band, the larger angle $\theta$ increases the resonant current path and thus causes a lower frequency.

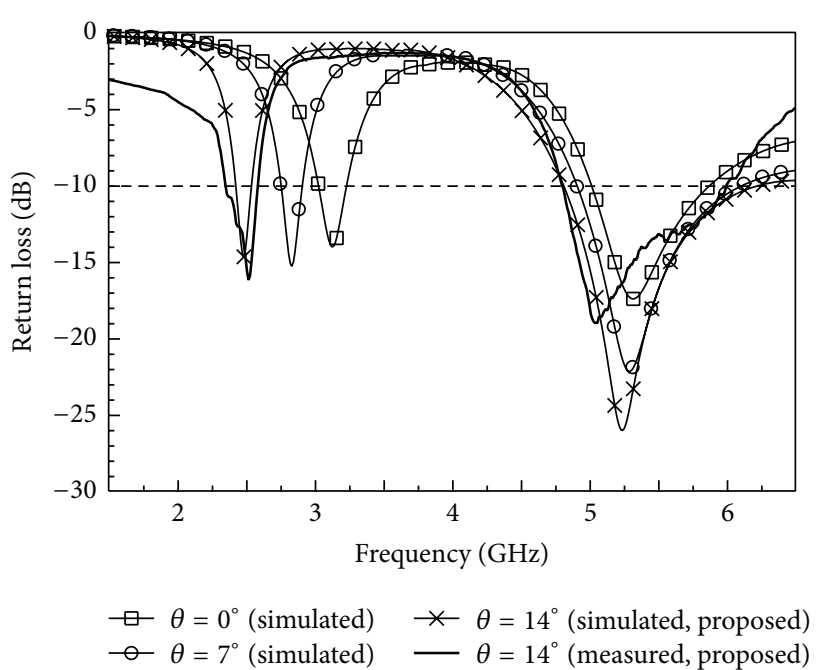

FIGURE 2: Simulated and measured return loss versus frequency for various $\theta$.

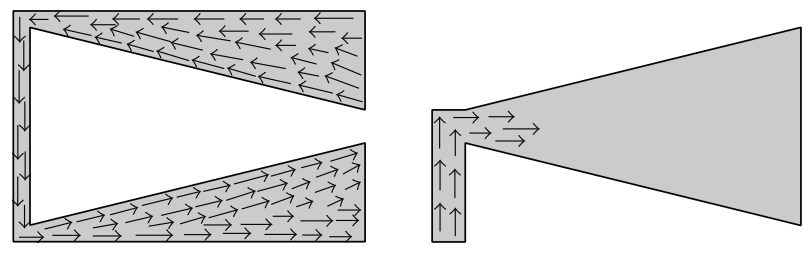

(a) $2.45 \mathrm{GHz}$

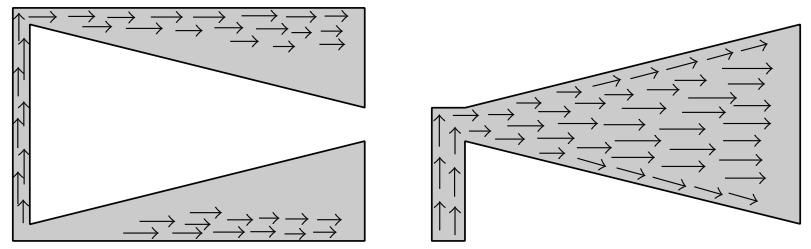

(b) $5.5 \mathrm{GHz}$

FIGURE 3: Simulated surface electrical current distributions obtained at (a) 2.45 and (b) $5.5 \mathrm{GHz}$ for proposed antenna.

For the upper band, the larger angle $\theta$ introduces a wider spreading range of resonant current paths along the hornshaped arm and thus causes a larger impedance bandwidth. The measured lower band has a $-10 \mathrm{~dB}$ impedance bandwidth of $225 \mathrm{MHz}(2321-2586 \mathrm{MHz})$, which covers the $2.4 \mathrm{GHz}$ band (2400-2484 MHz). Furthermore, the measured upper band has a $-10 \mathrm{~dB}$ impedance bandwidth of $1190 \mathrm{MHz}$ (4805-5995 MHz), which is sufficient for the $5 \mathrm{GHz}(5150-$ $5825 \mathrm{MHz}$ ) band. The results exhibit an acceptable agreement between the measurement and the simulation.

The excited surface current distributions simulated via Ansoft HFSS at 2.45 and 5.5 GHz are illustrated in Figures 3(a) and $3(\mathrm{~b})$, respectively. For the lower band excitation, the main surface current distribution is observed around the C-shaped arm and the total current length $(=28 \mathrm{~mm})$ is about a quarterwavelength corresponding to $2.45 \mathrm{GHz}$. For the upper bands, the main surface current distribution is noted on the hornshaped arm and the total current length $(=14.5 \mathrm{~mm})$ is about 

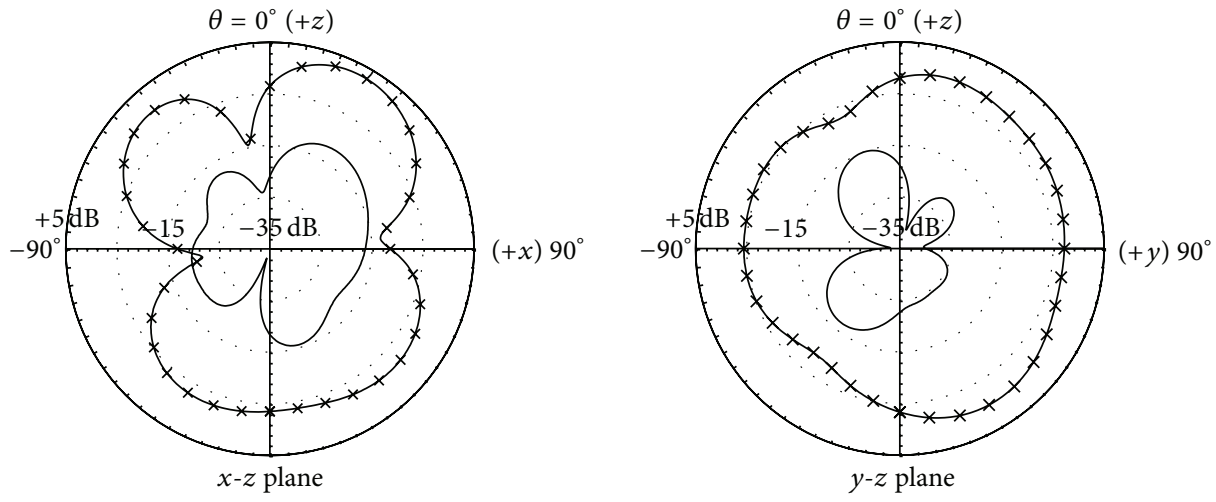

(a) $2.45 \mathrm{GHz}$
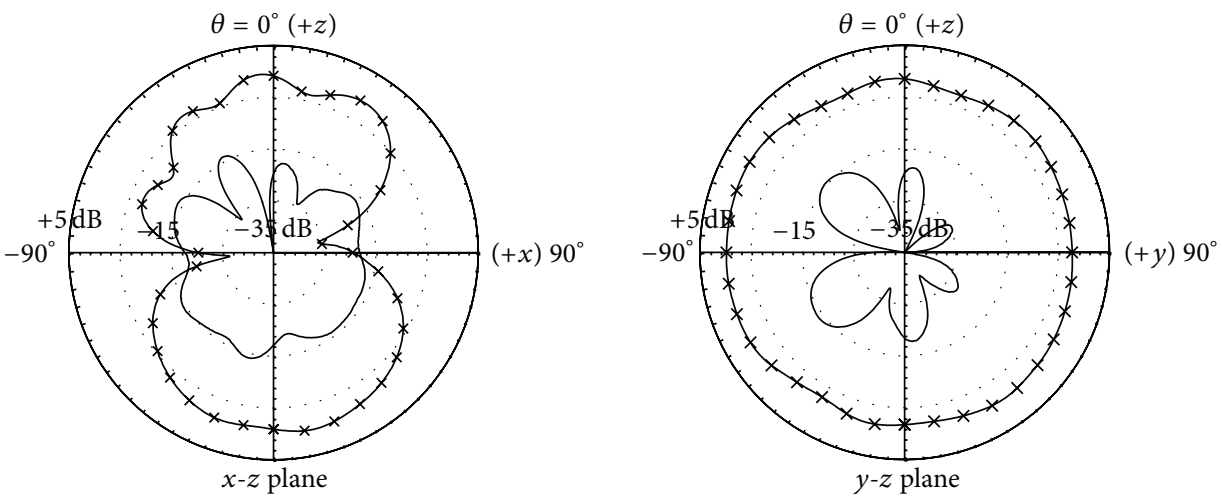

(b) $5.5 \mathrm{GHz}$

FIGURE 4: Measured radiation patterns of proposed antenna obtained at (a) 2.45 and (b) $5.5 \mathrm{GHz}$ - - X- copolarization - cross-polarization.

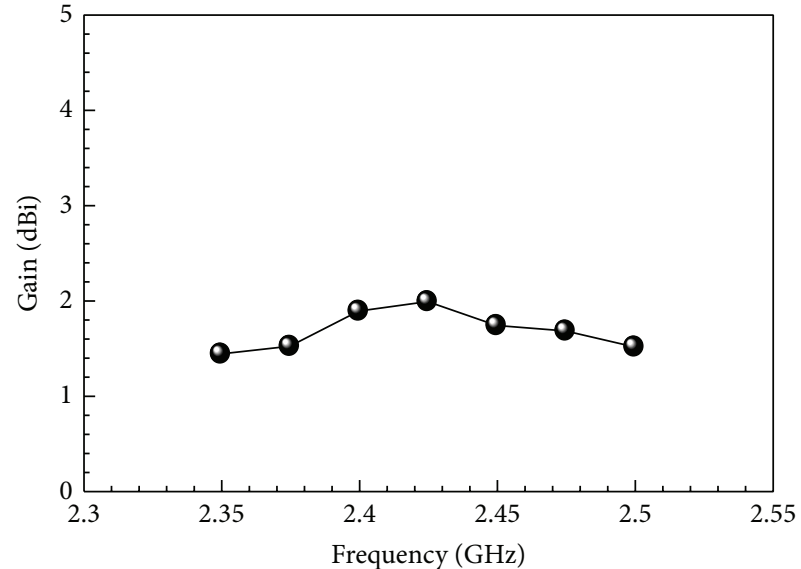

(a)

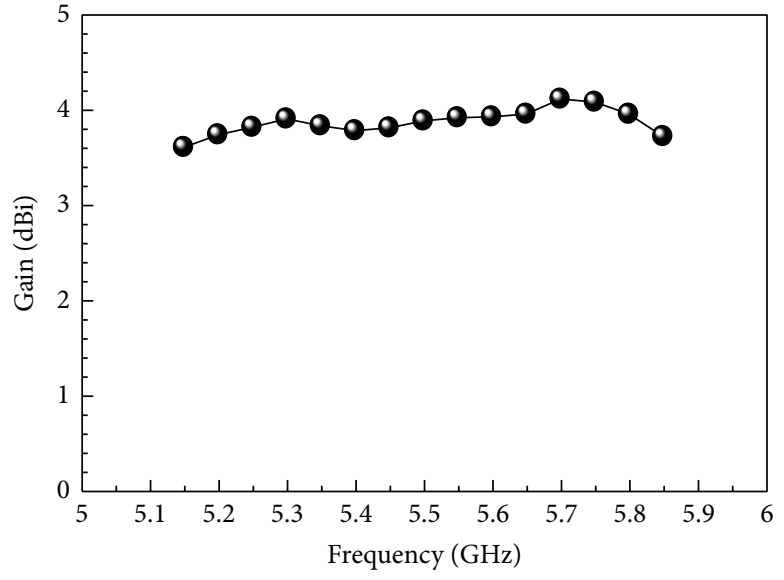

(b)

FIGURE 5: Measured antenna peak gain values versus frequency at (a) 2.35-2.5 and (b) 5.15-5.85 GHz of proposed dual-band antenna.

a quarter-wavelength corresponding to $5.5 \mathrm{GHz}$. Noticeably, the current on the horn-shaped arm mainly propagates in $x$ axis direction. The increasing $\theta$ did not change the current path in $x$-axis direction. On the other hand, the larger length of C-shaped arm due to the increase of $\theta$ causes a longer current path in the lower band. This feature clarifies that the varied $\theta$ mainly affect the lower band but not the upper band.
Figure 4 describes the measured radiation pattern at 2.45 and $5.5 \mathrm{GHz}$. A figure-of-eight radiation pattern in the $x-z$ plane and a nearly omnidirectional radiation pattern in the $y-z$ plane were obtained. The results in $x-z$ plane indicate that the radiation intensity in $\pm x$ directions is much smaller than that in $\pm z$ directions. A reasonable cross-polarization level is obtained due to the simple geometry of the proposed 
antenna. Figure 5 plots the measured antenna peak gain against frequency. The gain varies in a range of $1.4-2 \mathrm{dBi}$ at the lower band and 3.6-4 $\mathrm{dBi}$ at the upper band. The gain values within the operation bands are generally stable.

\section{Conclusion}

A dual-band dipole antenna with asymmetric arms for 2.4/5 $\mathrm{GHz}$ WLAN application has been successfully designed and implemented. Both $-10 \mathrm{~dB}$ bandwidths of the lower and upper bands are satisfied for IEEE $802.11 \mathrm{a} / \mathrm{b} / \mathrm{g}$ standards. Reasonable radiating performance of the proposed antenna is suitable for complex wave propagation environments. Furthermore, the antenna has a compact size of $7 \mathrm{~mm} \times 24 \mathrm{~mm}$, which makes it easy to be integrated with the RF terminals of the wireless devices for satisfying miniaturizing tendency.

\section{Conflict of Interests}

The authors declare that there is no conflict of interests regarding the publication of this paper.

\section{References}

[1] S.-H. Yeh, W.-C. Yang, and W.-K. Su, "2.4/5.2 GHz WLAN unequal-arms dipole antenna with a meandered strip for omnidirectional radiation patterns," in Proceedings of the IEEE Antennas and Propagation Society International Symposium, pp. 649-652, June 2007.

[2] C.-J. Tsai, W.-C. Chen, C.-H. Lin, J.-K. Guo, and C.-L. Lu, "An asymmetry printed WLAN/WiMax dipole antenna," in Proceedings of the 5th International Conference on Genetic and Evolutionary Computing (ICGEC '11), pp. 135-138, September 2011.

[3] Y.-J. Wang, Z.-Y. Lei, N. Zhang, D.-S. Cai, and Y.-F. Wang, "Asymmetric-arm printed dipole antenna for wlan applications," Microwave and Optical Technology Letters, vol. 54, no. 2, pp. 354-358, 2012.

[4] C. Y. D. Sim, H. Y. Chien, and C. H. Lee, "Dual-/triple-band asymmetric dipole antenna for WLAN operation in laptop computer," IEEE Transactions on Antennas and Propagation, vol. 61, no. 7, pp. 3808-3813, 2013.

[5] K. George Thomas and M. Sreenivasan, "A simple dual-band microstrip-fed printed antenna for WLAN applications," IET Microwaves, Antennas and Propagation, vol. 3, no. 4, pp. 687694, 2009.

[6] C. M. Peng, I. F. Chen, and C. H. Liu, "Multiband printed asymmetric dipole antenna for LTE/WLAN applications," International Journal of Antennas and Propagation, vol. 2013, Article ID 704847, 6 pages, 2013. 

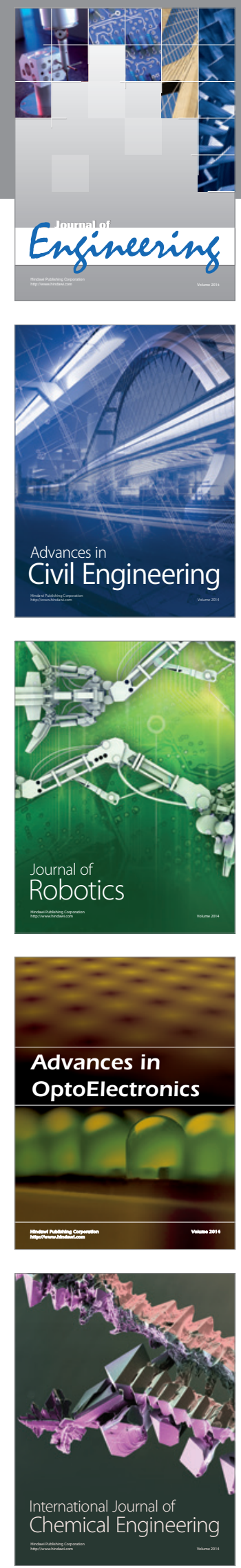

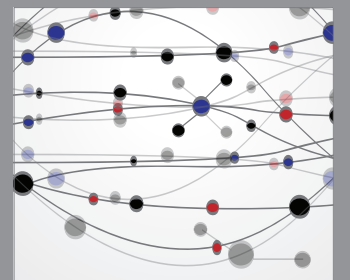

The Scientific World Journal
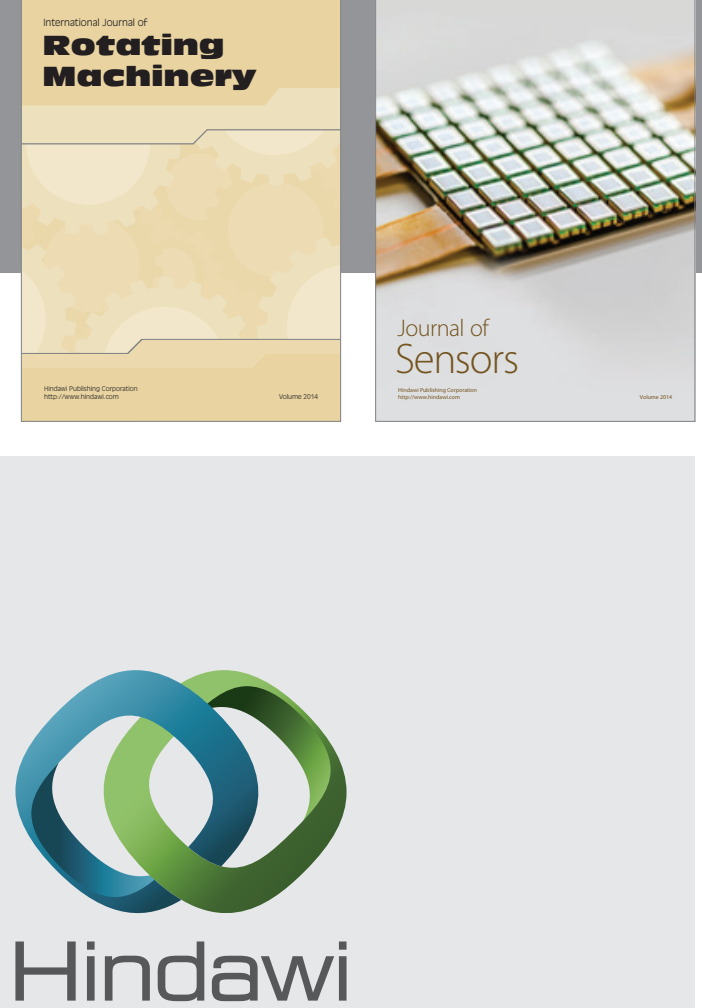

Submit your manuscripts at http://www.hindawi.com
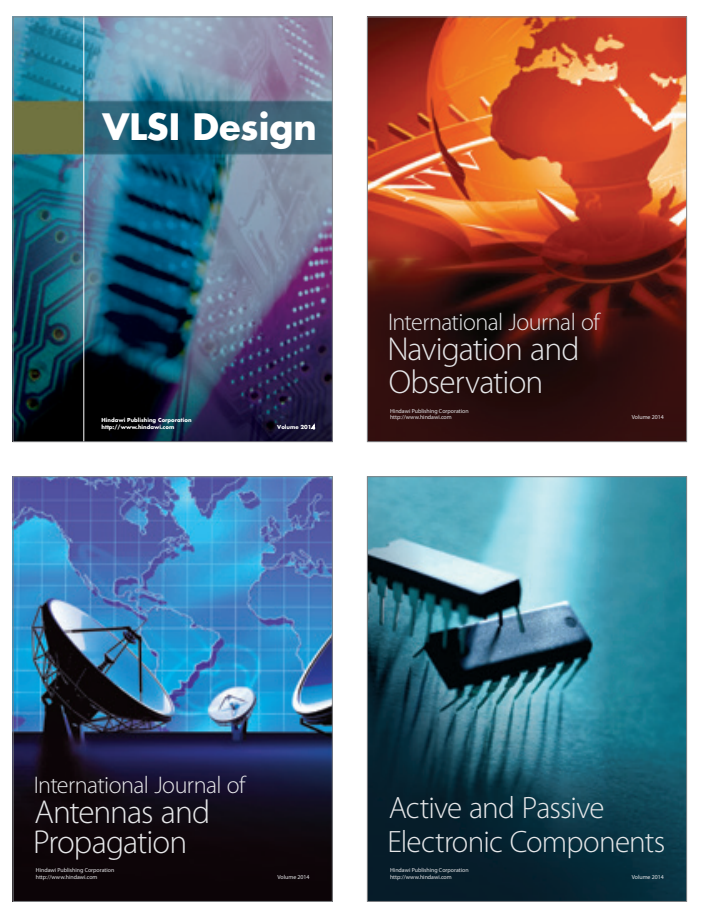
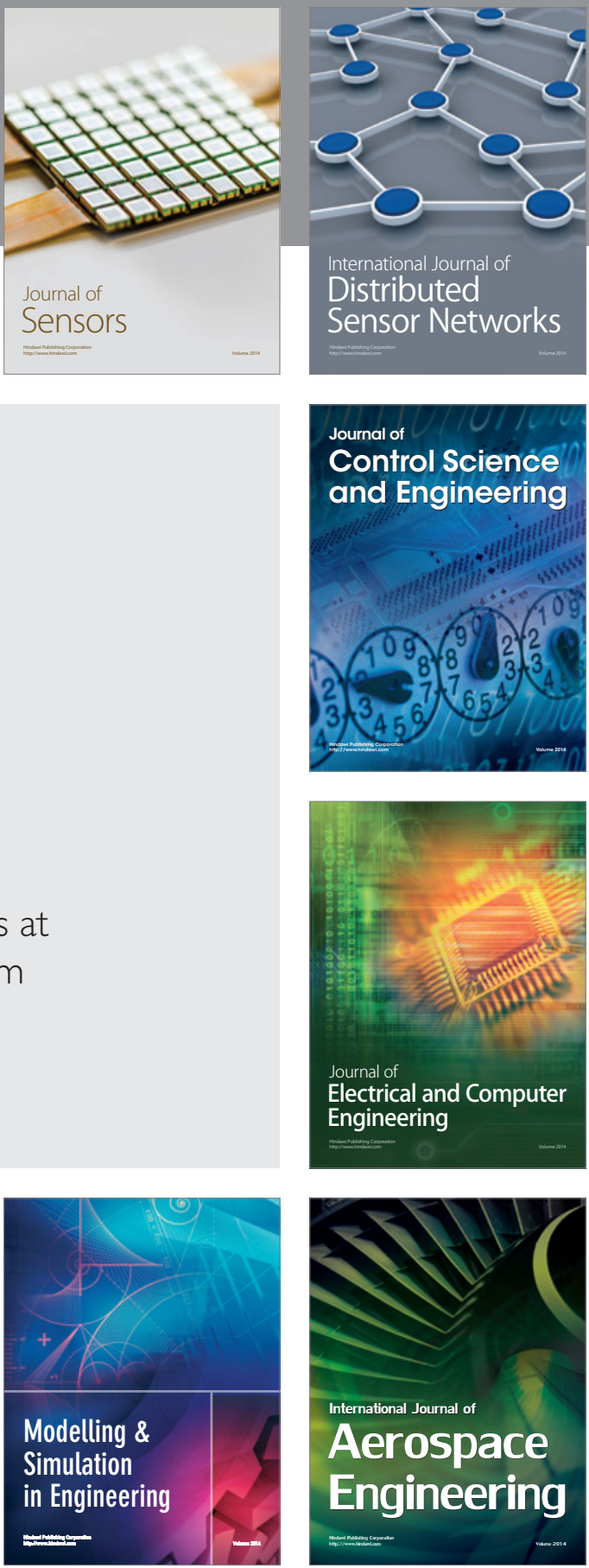

Journal of

Control Science

and Engineering
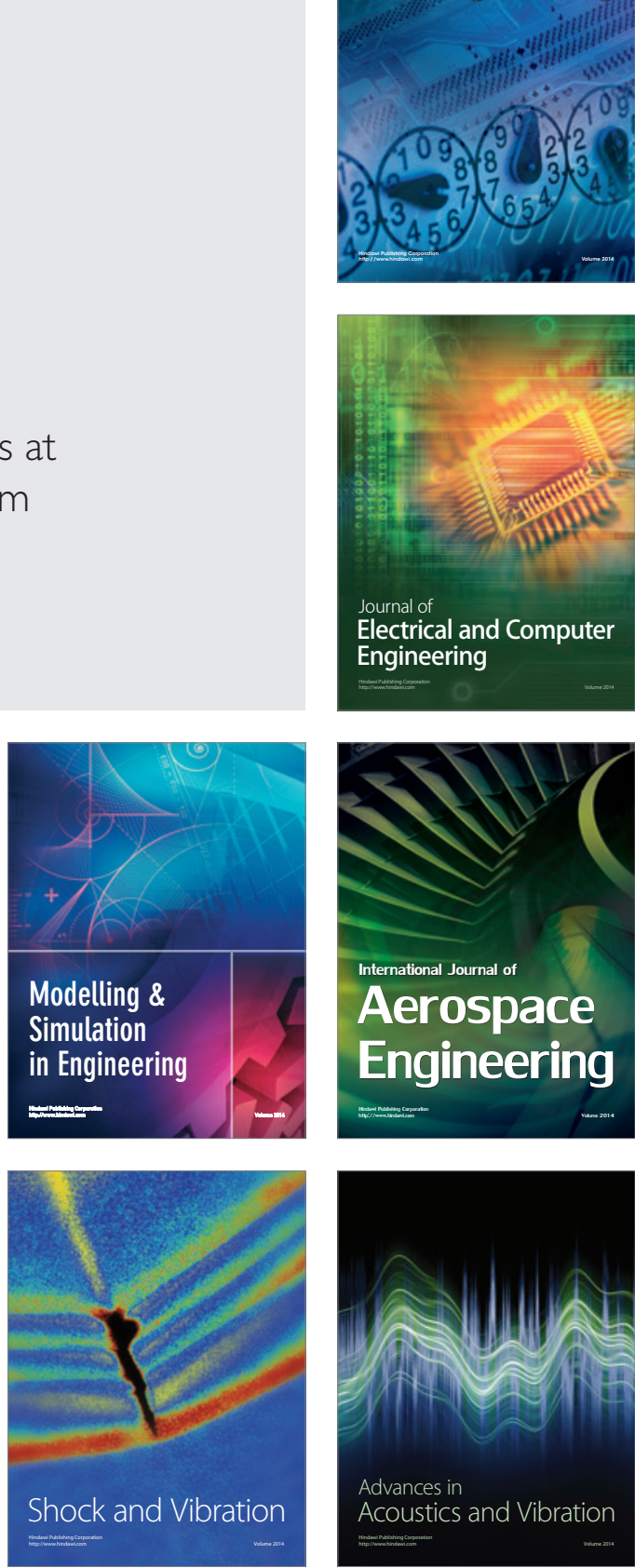